\title{
Coarctation of the aorta: nonsurgical treatment using stent implantation
}

Hak Lee Ang ${ }^{1,3}$, MD, MMed, Terence Chee Wen $\underline{\operatorname{Lim}}^{1}$, MBBS, MRCPCH, Cindy PP $\underline{\mathrm{Hia}}^{1}$, MBBS, MRCPCH, James $\underline{\text { Yip }}^{2}$, MBBS, MRCP, Swee Chye $\underline{\text { Quek }}{ }^{1}$, MD, FACC

INTRODUCTION Coarctation of the aorta (COA) accounts for $5 \%-8 \%$ of all congenital heart defects. If left untreated, most patients with significant CoA will have varying degrees of morbidity (e.g. hypertension, stroke, collateral formation and ventricular hypertrophy), possibly even mortality. Traditionally, treatment for this condition is surgical. Herein, we report stenting during catheterisation as an alternative nonsurgical treatment option for patients with CoA, and present the treatment outcomes of patients who underwent this treatment option.

METHODS We retrospectively reviewed four patients (2 men and 2 women; age range 20-41 years) who underwent CoA stenting under general anaesthesia for the treatment of native CoA or restenosis of CoA at our institution. Three patients had a 40-mm Palmaz stent inserted, while one had a 39-mm Cheatham-Platinum covered stent inserted. Angiography and measurement of pressure gradients were performed before and after stent implantation to ensure good treatment outcomes. RESULTS The patients' treatment outcomes were good, with a significant reduction in pressure gradients across the narrowed segments. Angiography showed relief of CoA. The patients were followed up for 1-3 years, during which no complications were noted.

CONCLUSION This is the first reported series in Singapore on the nonsurgical treatment of CoAs in adult patients using stents during interventional cardiac catheterisation. This less invasive procedure may lead to a new paradigm shift with regard to the treatment of CoA.

Keywords: angiogram, aortic coarctation, cardiac catheterisation, pressure gradients, stent

\section{INTRODUCTION}

Coarctation of the aorta (CoA) accounts for $5 \%-8 \%$ of all congenital heart defects. ${ }^{(1)}$ When $\mathrm{COA}$ is significant, it requires surgical or endovascular intervention. If left untreated, most patients with significant CoA will have varying degrees of morbidity (e.g. hypertension, stroke, formation of collateral vessels, ventricular hypertrophy and heart failure) and may not survive beyond the fourth decade of life..$^{(2)}$

Generally, the indication for intervention in $\mathrm{CoA}$ is a more than $50 \%$ decrease in lumen diameter at the narrowed site and/or a pressure gradient of more than $20 \mathrm{mmHg}$ at rest. Although CoA is usually detected in children, it may recur or be diagnosed in adolescents and adults. Surgical treatment of CoA was first described in $1945,{ }^{(3)}$ and till today, remains the treatment of choice. However, recently, less invasive methods such as balloon dilation and/or stent implantation have been used to treat CoA in elderly patients. ${ }^{(4,5)}$

Compared to balloon angioplasty, stent implantation has a reduced risk of aortic tears, and results in a lower residual gradient. ${ }^{(4,5)}$ Stent implantation also improves luminal diameter, sustaining the procedure's haemodynamic benefit, ${ }^{(6-13)}$ though hypertension may persist in some patients. ${ }^{(14,15)}$ Even though CoA stenting is effective, ${ }^{(16-18)}$ it is a technically challenging procedure, and local data on the approach is needed. Therefore, we aimed to study a series of patients with CoA treated nonsurgically, focusing on their resultant $\mathrm{CoA}$ gradient and $\mathrm{CoA}$ diameter, so as to document the implementation of this procedure in a local centre.

\section{METHODS}

From January 2007 to December 2009, we retrospectively reviewed four patients who underwent CoA stenting at our institution for the treatment of native $\mathrm{CoA}$ or restenosis of $\mathrm{CoA}$ after surgical repair. Of the four patients, two were on follow-up post coarctation surgery. Of the remaining two patients, one was diagnosed with CoA due to hypertension, and the other, due to heart murmur. The data, including treatment outcomes, of these four patients was extracted from our institution's medical records and catheter studies.

At our institution, sedation of patients undergoing endovascular stenting for CoA (Fig. 1) is achieved via general anaesthesia, as it is imperative that patients are kept still, so as to prevent movement that may cause stent migration during balloon inflation. Aortography is performed to measure the narrowest diameter, the length of CoA, and the diameters above and below the CoA, so as to guide the selection of the appropriate stent. The pressure gradient across the CoA is measured. The selected stent is then manually crimped onto a selected high-pressure balloon. The balloon-in-balloon catheter is used, as this gives better control during inflation. Angiography is performed to check the position of the stent across the CoA prior to inflation of the balloon catheter. Upon confirmation of a satisfactory position, the balloon is inflated to expand the stent, broadening the narrowed segment. Thereafter, the pressure gradient across the stent is measured, and angiography is performed to assess the achieved outcome. Fig. 2 shows the result following the procedure.

${ }^{1}$ Department of Paediatrics, National University of Singapore, ${ }^{2}$ National University Heart Centre, Singapore, ${ }^{3}$ Department of Paediatrics, University of Malaya, Kuala Lumpur, Malaysia Correspondence: Dr Quek Swee Chye, Senior Consultant and Head, Division of Cardiology, Department of Paediatrics, National University of Singapore, Lower Kent Ridge Road, Singapore. swee_chye_quek@nuhs.edu.sg 

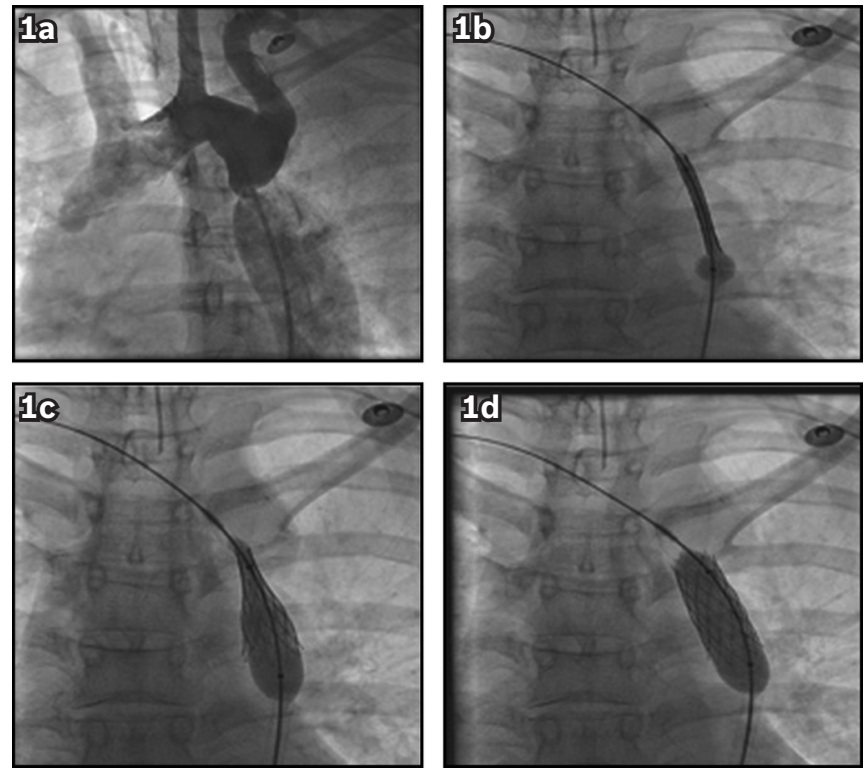

Fig. 1 Aortograms show the method for stenting. (a) Discrete coarctation of the aorta $(\mathrm{COA})$. (b) The stent is crimped onto the inflating balloon catheter and delivered to the narrowed site. (c \& d) The balloon catheter is inflated at the narrowed segment to abolish CoA.

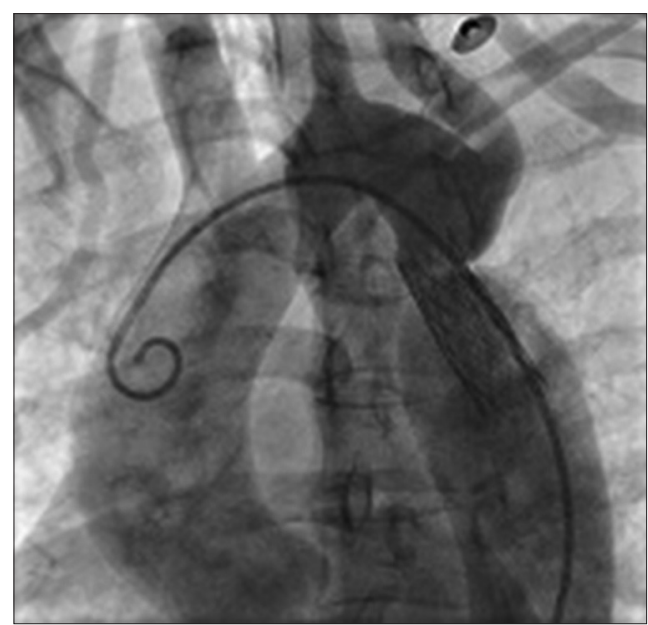

Fig. 2 Repeat angiogram and pressure measurement performed after stent implantation shows an increase in the diameter of the aorta till the desired size is achieved, via stent implantation.

\section{RESULTS}

The demographics of the four patients are presented in Table I. CoA is strongly associated with bicuspid aortic valve; in our study cohort of four patients, three had concomitant bicuspid aortic valve. A stent was implanted in each patient. Three patients had a 40-mm Palmaz (Cordis Corporation, Johnson \& Johnson, Miami, FL, USA) stent implanted, while one had a 39-mm Cheatham-Platinum (NuMED Inc, New York, USA) covered stent implanted. One patient required re-dilation of the stent one year later to achieve a more optimal result at the narrowed site.

The treatment outcomes were good, with significant reduction in pressure gradient across the narrowed segments. After the procedure, two patients had no significant pressure gradient (i.e. $<5 \mathrm{mmHg}$ ) across the stent. One patient with a post-stenting pressure gradient of $14 \mathrm{mmHg}$ underwent further re-dilation of the stent a year later with good results. At the time of writing, the patient
Table I. Summary of patient demographics.

\begin{tabular}{lc}
\hline Measurement & Result \\
\hline No. of patients & 4 \\
Median age (range) (yrs) & $29.3(20-41)$ \\
Male to female ratio & $2: 2$ \\
Ratio of native CoA to restenosis* & $2: 2$ \\
\hline
\end{tabular}

*Postsurgical repair. CoA: coarctation of the aorta

Table II. Pre- and post-stenting coarctation of the aorta (CoA) gradients and diameters.

\begin{tabular}{lcccccc}
\hline Patient & \multicolumn{2}{c}{ CoA gradient $(\mathbf{m m H g})$} & & \multicolumn{2}{c}{ CoA diameter $(\mathbf{m m})$} \\
\cline { 2 - 3 } \cline { 5 - 6 } & Pre-stenting & Post-stenting & & Pre-stenting & Post-stenting \\
\hline 1 & 14 & 0 & & 8 & 24 \\
2 & 34 & 4 & & 4 & 12 \\
3 & 15 & 11 & & 10 & 22 \\
$4^{*}$ & 24 & 14 & & 9 & 14 \\
Mean & 22 & 7 & & 8 & 18 \\
\hline
\end{tabular}

*Patient 4 underwent re-dilation of the stent

with a post-stenting pressure gradient of $11 \mathrm{mmHg}$ was in the midst of being followed up on, and may need re-dilation of the stent in the near future (Table II). Angiography revealed relief of CoA in all patients. For all the patients in our study cohort, the post-stenting diameter was significantly increased compared to the pre-stenting diameter (Table II). There was no significant complication either during or immediately after the procedure, except for Patient 1, who developed right common femoral artery thrombosis. However, Patient 1 recovered well after thrombectomy. The patients in our cohort were followed up for 1-3 years, with no complications noted. None of the patients required antihypertensive treatment before or after endovascular stenting.

\section{DISCUSSION}

The treatment outcomes of the nonsurgical treatment for CoA were good in our study cohort. There were no major complications noted during the short- to mid-term follow-ups. To the best of our knowledge, this is the first report of nonsurgical, transcatheter stent implantation in adult patients in Singapore for the treatment of CoA. In our literature search, similar encouraging results have been reported in other countries Harrison et $\mathrm{al}^{(4)}$ found that the mean peak pressure gradient of $46 \pm 20 \mathrm{mmHg}$ at baseline was reduced to a mean gradient of $4 \pm 6$ (range $0-26$ ) $\mathrm{mmHg}$ at follow-up 1-3 years later. In Hamdan et al's study, ${ }^{(5)}$ the peak systolic pressure gradient measured at catheterisation decreased from $32 \pm 12 \mathrm{mmHg}$ to $4 \pm 11 \mathrm{mmHg}$, while the echocardiographic Doppler gradient decreased from $51 \pm 26 \mathrm{mmHg}$ to $13 \pm 11 \mathrm{mmHg}$ at follow-up. Other similar reports showed significant improvement in the pressure gradients ${ }^{(19-21)}$ and CoA diameters ${ }^{(14,19,22)}$ before and after stent implantation.

The patient in our study cohort who needed re-dilation had severe CoA, with a pressure gradient of $24 \mathrm{mmHg}$. Re-dilation has also been reported in other series..$^{(4,5,22,23)} \mathrm{A}$ higher initial pressure gradient is indicative of a more severe $\mathrm{CoA}$, which may be predictive of a future requirement for re-dilation. It is also 
safer to be more conservative with the initial balloon inflation, and return later for re-dilation with a larger balloon, which can usually be done successfully. Pre-dilation before stenting may also be helpful in cases of very severe CoA. ${ }^{(24)}$

One patient in our study developed a post-procedure complication associated with right common femoral artery thrombosis. Another well-recognised complication is the persistence of hypertension in patients with CoA. ${ }^{(19,20,25)}$ Serious complications have also been reported with stent implantation. ${ }^{(18)}$ The complications associated with CoA stenting include damage to the femoral artery and thrombus formation due to the large sheaths and balloon catheters required. Balloon catheter rupture is another potential complication. At the time of stent implantation, there is also the risk of inappropriate placement and/or stent migration following balloon dilation. As stents are frequently placed near carotid vessels, there is also a risk of cerebrovascular events. ${ }^{(26)}$ Other possible complications include acute aortic rupture, aortic dissection and aneurysm formation.

Our data suggests that there is significant improvement in both CoA gradient and diameter after stent implantation, similar to what has been previously reported..$^{(4,5,14,19-22)}$ However, in stent implantation, the suitability of the procedure in relation to the age of the patient is an important consideration. The small calibre of vessels in children would make stent implantation difficult, possibly rendering surgery or balloon angioplasty a better option in children with CoA. In adolescents and adults, stenting would confer advantages such as superior and longer lasting results than that attained through balloon angioplasty. Indeed, either balloon angioplasty or stent implantation may be applicable to native CoA or restenosis following previous CoA surgery. Native $\mathrm{CoA}$ in adults is rare as patients are now diagnosed and treated early. However, stent implantation is typically not performed in children. This is because as the aorta continues to grow as the child grows, multiple attempts at re-dilation would have to be performed. The consequences of multiple attempts at stent re-dilation is unknown. Another disadvantage of stenting is the use of large sheaths to accommodate the balloon catheter and stent, which may damage the femoral vessels in young children. However, the femoral artery and aorta are larger in older patients, making such patients more suitable candidates for this technique.

In conclusion, therapeutic treatment of $\mathrm{CoA}$ through the use of stents during interventional cardiac catheterisation represents a new paradigm of treatment in Singapore for older patients with $\mathrm{CoA}$, a condition that previously required surgical management. With increased expertise, improved techniques and better devices, it is envisaged that stenting for CoA will become a desired treatment option in suitable patients in the future.

\section{ACKNOWLEDGEMENT}

We thank Dr Dimple Rajgor for her assistance in the literature search, and the writing, editing, formatting and submission of the manuscript.

\section{REFERENCES}

1. Hoffman JI, Kaplan S. The incidence of congenital heart disease. J Am Coll Cardiol 2002; 39:1890-900.

2. Campbell M. Natural history of coarctation of the aorta. Br Heart J 1970; 32:633-40.

3. Crafoord C, Nylin G. Congenital coarctation of the aorta and its surgical treatment. J Thorac Surg 1945; 14:347-61.

4. Harrison DA, McLaughlin PR, Lazzam C, Connelly M, Benson LN. Endovascular stents in the management of coarctation of the aorta in the adolescent and adult: one year follow up. Heart 2001; 85:561-6.

5. Hamdan MA, Maheshwari S, Fahey JT, Hellenbrand WE. Endovascular stents for coarctation of the aorta: initial results and intermediate-term follow-up. J Am Coll Cardiol 2001; 38:1518-23.

6. De Lezo JS, Sancho M, Pan M, et al. Angiographic follow-up after balloon angioplasty for coarctation of the aorta. J Am Coll Cardiol 1989; 13:689-95.

7. Rico J, Sobrino N, Calvo L, et al. [Percutaneous transluminal angioplasty in aortic coarctation in young adults]. Rev Esp Cardiol 1989; 42: 415-7. Spanish.

8. Kulick DL, Kotlewski A, Hurvitz RJ, Jamison M, Rahimtoola SH. Aortic rupture following percutaneous catheter balloon coarctoplasty in an adult. Am Heart J 1990; 119:190-3.

9. Fawzy ME, Sivanandam V, Galal O, et al. One- to ten-year follow-up results of balloon angioplasty of native coarctation of the aorta in adolescents and adults. J Am Coll Cardiol 1997; 30:1542-6.

10. Phadke K, Dyet JF, Aber CP, Hartley W. Balloon angioplasty of adult aortic coarctation. Br Heart J 1993; 69:36-40.

11. Fletcher SE, Nihill MR, Grifka RG, O'Laughlin MP, Mullins CE. Balloon angioplasty of native coarctation of the aorta: midterm follow-up and prognostic factors. J Am Coll Cardiol 1995; 25:730-4.

12. Schräder R, Bussmann WD, Jacobi V, Kadel C. Long-term effects of balloon coarctation angioplasty on arterial blood pressure in adolescent and adult patients. Cathet Cardiovasc Diagn 1995; 36:220-5.

13. Biswas PK, Mitra K, De S, et al. Follow-up results of balloon angioplasty for native coarctation of aorta. Indian Heart J 1996; 48:673-6.

14. Eicken A, Pensl U, Sebening W, et al. The fate of systemic blood pressure in patients after effectively stented coarctation. Eur Heart J 2006; 27:1100-5.

15. Musto C, Cifarelli A, Pucci E, et al. Endovascular treatment of aortic coarctation: long-term ef fects on hypertension. Int J Cardiol 2008; 130:420-5.

16. Macdonald S, Thomas SM, Cleveland TJ, Gaines PA. Angioplasty or stenting in adult coarctation of the aorta? A retrospective single center analysis over a decade. Cardiovasc Intervent Radiol 2003; 26:357-64.

17. Forbes TJ, Garekar S, Amin Z, et al. Procedural results and acute complications in stenting native and recurrent coarctation of the aorta in patients over 4 years of age: a multi-institutional study. Catheter Cardiovasc Interv 2007; 70:276-85.

18. Golden AB, Hellenbrand WE. Coarctation of the aorta: stenting in children and adults. Catheter Cardiovasc Interv 2007; 69:289-99.

19. Moltzer E, Roos-Hesselink JW, Yap SC, et al. Endovascular stenting for aortic (re) coarctation in adults. Neth Heart J 2010; 18:430-6.

20. Mahadevan VS, VondermuhII IF, Mullen MJ. Endovascular aortic coarctation stenting in adolescents and adults: angiographic and hemodynamic outcomes. Catheter Cardiovasc Interv 2006; 67:268-75.

21. Tanous D, Collins N, Dehghani P, Horlick EM, Benson LN. Covered stents in the management of coarctation of the aorta in the adult: initial results and 1-year angiographic and hemodynamic follow-up. Int J Cardiol 2010; 140:287-95.

22. Chessa M, Carrozza M, Butera G, et al. Results and mid-long-term followup of stent implantation for native and recurrent coarctation of the aorta. Eur Heart J 2005; 26:2728-32.

23. Egan M, Holzer RJ. Comparing balloon angioplasty, stenting and surgery in the treatment of aortic coarctation. Expert Rev Cardiovasc Ther 2009; 7:1401-12.

24. Qureshi AM, McElhinney DB, Lock JE, et al. Acute and intermediate outcomes, and evaluation of injury to the aortic wall, as based on 15 years' experience of implanting stents to treat aortic coarctation. Cardiol Young 2007; 17:307-18.

25. Chen SS, Donald AE, Storry C, et al. Impact of aor tic stenting on peripheral vascular function and daytime systolic blood pressure in adult coarctation. Heart 2008; 94:919-24.

26. Karl TR. Surgery is the best treatment for primary coarctation in the majority of cases. J Cardiovasc Med (Hagerstown) 2007; 8:50-6. 